\title{
二層弾性地盤上の長方形剛基礎底面の複素剛性

\author{
DYNAMIC STIFFNESS UNDER RIGID RECTANGULAR FOUNDATIONS \\ RESTING ON AN ELASTIC TWO-LAYERED MEDIUM
}

\author{
北村 泰寿*・桜井春 輔** \\ By Yasutoshi KITAMURA and Shunsuke SAKURAI
}

\begin{abstract}
This paper deals with the dynamic stiffness (i. e., the complex stiffness) under rigid rectangular foundations resting on an elastic two-layered medium. This is a problem belonging to mixed boundary value problems which are not easily solved by an analytical approach. To overcome the difficulties of analysis the authors employ a numerical method, in which the contact area of the foundation is divided into a finite number of rectangular sub-regions, and a system of linear simultaneous equations with respect to the unknown contact pressures is derived by introducing the influence functions. In this paper the authors mainly investigate the effects of the layering on the dynamic stiffness and the difference in the dynamic stiffness between the relaxed and welded boundary conditions on the contact plane.
\end{abstract}

\section{1. まえがき}

基礎構造物の動的設計において, 地盤の複素剛性を評 価することは重要な問題である. 地盤を波動伝播媒体と して取り扱う理論的研究は Reissnerによる円形フーチ ングの振動問題に始まり, 以来数多くの研究がなされて いる ${ }^{1}$. これらの研究は, 構造物底面下の接触圧の取り 扱いによって, (1)接触圧の分布形状を仮定して変位を求 めたもの, (2)接触圧を未知関数亡する積分方程式を解い たものに分けられる. 前者は, 構造物底面下の接触圧分 布を一様, 剛体, 放物線等の分布に仮定して, 加振平面 の変位を求める応力境界值問題となるたと六22 -5). また, 後者は, 構造物を剛体と仮定して, 構造物底面下の境界 条件を変位で与えその他の地表面の条件を応力零で与え る混合境界值問題となる. 剛体帯や剛円盤のような簡単 な形状の場合には, 積分方程式を解析的に変形する方法 が用いられているたとえ(゙6) 9). 一方, 矩形底面も含めた任 意形状の底面を有する剛体構造物の場合には, 積分方程 式を直接離散化する手法が利用されている ${ }^{10) ~ 20)}$.

* 正会員 工博 神戸大学助教授 工学部土地造成工学研究 施設 ( 1657 神戸市灘区六甲台町)

** 正会員 $\mathrm{Ph}$. D. 工博 神戸大学教授 工学部土木工学科 (同上)
ところで, 最近のように構造物が重要かつ巨大化する 傾向に対しては, 構造物の大きさと比較して地盤の多層 性を無視することは妥当ではない。これまでの研究にお いて，地盤を層状弾性体として取り扱っているものはい くつかみられるがたとえば5),91,19)，多くのものは地盤を半無 限弾性体にモデル化している.したがって, 今後地盤を 層状弾性体と考えた構造物一地盤系の動的相互作用問題 に対する研究がますます重要となろう．このような状況 において, 本論文は, 既報の著者らの論文 21) の成果 を利用して, 二層弾性地盤上の長方形剛基礎底面の複素 剛性を求めたものである. 特に, 本論文では, 地盤の層 剛性比, 表層厚, 剛基礎底面の形状および構造物底面と 地盤の接触面における密着性（す なわち, 加振方向以外の変位の拘 束(11) などが複素剛性に及ぼす影 響について調べる.

\section{2. 解析手法}

Fig. 1 に示すように, 二層弾性

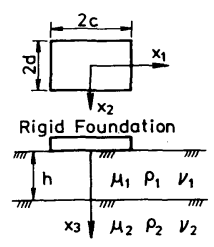

Fig. 1 Coordinate system.
注 1）鉛直，ロッキング振動に対しては構造物と地盤の接触 面の摩擦による水平変位の拘束, 水平振動に対しては水 平加振方向以外の変位の拘束を本論文では接触面の変位 に対する拘束と総称する. 
地盤の表面に底面積 $S(=2 c \times 2 d)$ の剛体構造物が存在 する場合を考える．構造物底面の接触圧分布は，Green 関数を用いて得られる次式の積分方程式を解くことに よって求まる.

$$
\begin{array}{r}
u_{i}\left(x_{1}, x_{2}\right)=\sum_{j=1}^{3} \iint_{S} G_{i j}\left(x_{1}, x_{2} \mid \xi_{1}, \xi_{2}\right) q_{j}\left(\xi_{1}, \xi_{2}\right) \cdot d \xi_{1} d \xi_{2} \\
(i=1,2,3) \cdots \cdots \cdots \cdots(
\end{array}
$$

ここで， $u_{i} ， q_{j}$ はそれぞれ接触面 $S$ 内の既知変位，未 知接触圧で, 添字 $i, j$ は $x_{1}, x_{2}, x_{3}$ 方向の成分を表わす. また, $G_{i j}\left(x_{1}, x_{2} \mid \xi_{1}, \xi_{2}\right)$ は二層弾性地盤の Green 関数で, 表層厚 $h$, 表層, 下層のせん断弾性係数 $\mu_{1}, \mu_{2}$, 密度 $\rho_{1}$, $\rho_{2}$, ポアソン比 $\nu_{1}, \nu_{2}$ (Fig. 1 参照) および加振振動数 に関係する ${ }^{22)}$.

式（1）は解析的に解けないため, 接触面を有限個の 要素に分割し，この分割モデルに対して式（1）を次式 のように離散化する ${ }^{15)}$.

$$
u_{i}(l)=\sum_{j=1}^{3} \sum_{k=1}^{N} \overline{G_{i j}}(l \mid k) q_{j}(k) \quad(l=1,2, \cdots, N) \cdots \cdots
$$

ここで, $N$ は分割要素の総数, $u_{i}(l)$ は要素 $l$ の中央変 位, $q_{j}(k)$ は要素 $k$ の等分布接触圧の大きさを表わす. また, $\overline{G_{i j}}(l \mid k)$ は Green 関数を要素 $k$ について面積分 して得られるもので，次式で表わされる.

$$
\overline{G_{i j}}(l \mid k)=\iint_{s_{k}} G_{i j}\left(x_{1}^{(l)}, x_{2}^{(l)} \mid \xi_{1}, \xi_{2}\right) d \xi_{1} d \xi_{2} \cdots
$$

ここで, $S_{k}$ は分割要素 $k$ の面積, $\left(x_{1}^{(l)}, x_{2}^{(l)}\right)$ は要素 $l$ の 中央点の座標である。

いま，各要素の変位 $u_{i}(l)$ が既知であれば，式 $(2)$ から各要素の接触圧 $q_{j}(k)$ を末知量とする多元連立一 次方程式が得られる.さらに, 複素剛性は, 鉛直振動, ロッ キング振動（ $x_{2}$ 軸回り）および水平振動 $\left(x_{1}\right.$ 方向）に 対して，それぞれ次式によって求められる。

$$
\begin{aligned}
& K_{V V}\left(a_{0}\right)=\sum_{k}^{N} S_{k} q_{3}(k) / \Delta_{3} \\
& K_{M M}\left(a_{0}\right)=\sum_{k}^{N} S_{k} q_{3}(k) x_{1}^{(k)} / \Omega_{2} \\
& K_{H H}\left(a_{0}\right)=\sum_{k}^{N} S_{k} q_{1}(k) / \Delta_{1}
\end{aligned}
$$

ここで, $a_{0}=\omega c / V_{s 1}, \Delta_{1}, \Delta_{3}$ は $x_{1}, x_{3}$ 方向の変位, $\Omega_{2}$ は $x_{2}$ 軸回りの回転角, $x_{1}^{(k)}$ は $x_{2}$ 軸から要素 $k$ の中 央点までの $x_{1}$ 軸に沿う距離, $\omega$ は加振円振動数， $c$ は 剛基礎底面の $x_{1}$ 方向の半幅， $V_{S 1}$ は表層の横波の伝播 速度である。

ところで，層状弾性地盤の場合，表面波は分散性を示 すことが知られている. Fig. 2 は二層弾性地盤の分散曲 線，すなわち式（1）および（3）の被積分関数に現わ れる分母の根を示したものである．なお，縦軸の $V_{R}$, $V_{L}$ はそれぞれ Rayleigh 型, Love 型の表面波の伝播速 度を意味する。半無限弾性地盤 $\left(\mu_{2} / \mu_{1}=1\right)$ の場合には

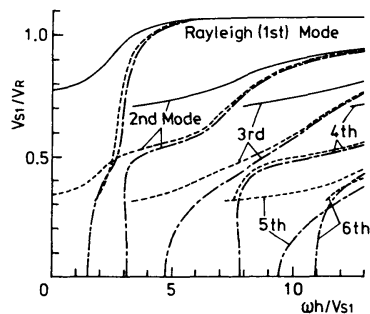

a) Rayleigh Waves

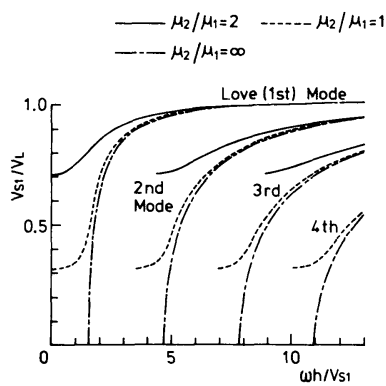

b) Love Waves

Fig. 2 Dispersion curves of elastic two-layered medium $\left(\nu_{1}=\nu_{2}=1 / 3, \quad \rho_{1}=\rho_{2}\right)$.

$V_{S_{1}} / V_{R} \doteqdot 1.072$ の 1 根のみしか存在しないが，二層弾性 地盤の場合には無次元振動数 $\omega h / V_{s 1}$ の値によって複数 個の根が存在することになる。このため，式（3）の積 分は複数個の特異点を含む積分となり，この数值積分は 相当の困難を伴う。

\section{3. 剛体帯に対する複素剛性}

長方形底面の辺長比 $d / c$ (Fig. 1 参照）が非常に大き くなれば，地盤の層剛性比 $\left(\mu_{2} / \mu_{1}\right)$, 表層厚および構造 物之地盤の接触面における加振方向以外の変位の拘束

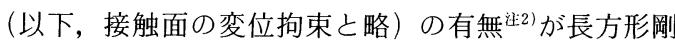
基礎底面の複素剛性に及ぼす影響は，剛体帯に対する複 素剛性の場合と類似の傾向を示すものと考えられる。し たがって，ここでは長方形底面をもつ剛基礎の極端な例 として，剛体帯の複素剛性に対していくつかの検討を行 う.

半無限弾性地盤の場合, Karasudhi $ら^{6)}$, Luco $ら^{77}$ に よって剛体帯の複素剛性が求められている. Fig. 3 は, 本論文の数值解法の検証も兼称て, $\mu_{2} / \mu_{1}=1$ としたと きの解と Karasudhi らの結果と比較したものである. 同図より，ロッキング振動の複素剛性において本論文の 数值解法の精度が若干悪くなっているが，接触面の分割 数が $N=20$ 程度で十分な精度の結果が得られていると

注 2）本論文では，注 1）に定義した用語のもとで，接触面 に㧍ける加振方向以外の変位を許す場合を変位拘束なし (Relaxed Case)，また加振方向以外の変位を 0 とする 完全拘束の場合を変位拘束あり (Welded Case) とよぶ. 


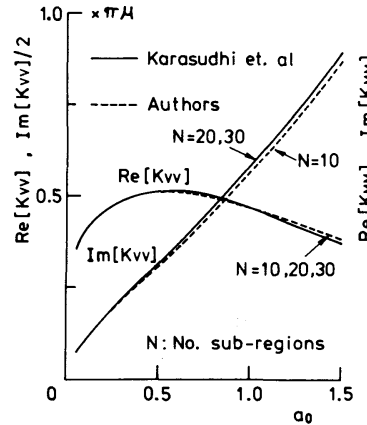

a) Vertical Vibration

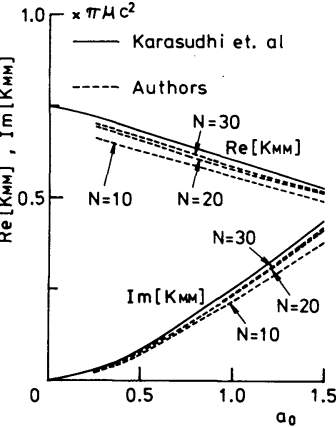

b) Rocking Vibration

Fig. 3 Comparison of dynamic stiffnesses for rigid strip (Half- space, Relaxed case, $\nu=1 / 3$ ).

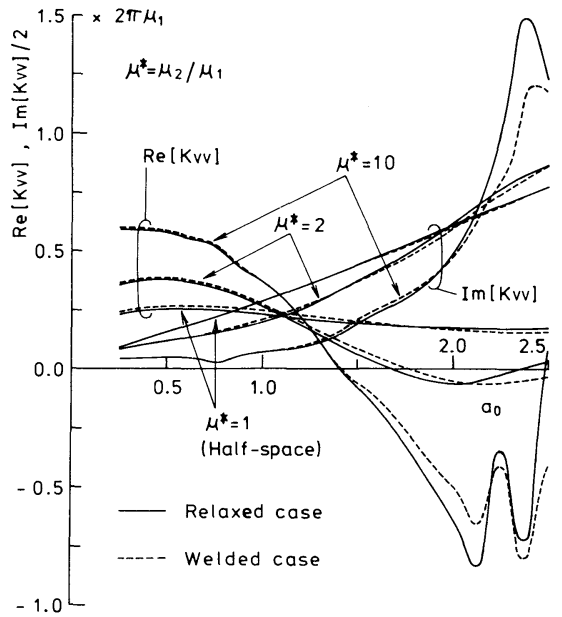

Fig. 4 Effect of $\mu_{2} / \mu_{1}$ on vertical dynamic stiffnesses for rigid strip $\left(h / c=2, \quad \nu_{1}=\nu_{2}=1 / 3, \rho_{1}=\rho_{2}\right)$.

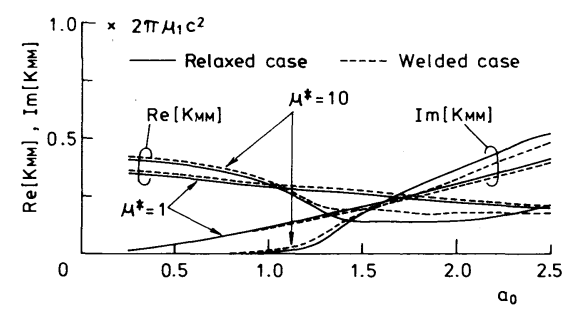

Fig. 5 Effect of $\mu_{2} / \mu_{1}$ on rocking dynamic stiffnesses for rigid strip $\left(h / c=2, \nu_{1}=\nu_{2}=1 / 3, \rho_{1}=\rho_{2}\right)$.

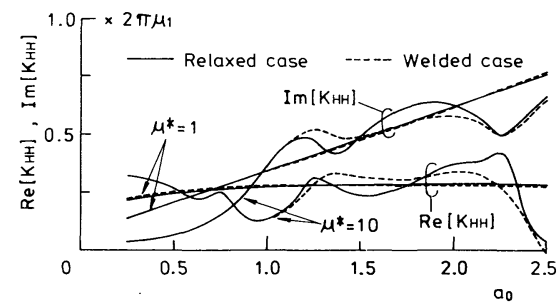

Fig. 6 Effect of $\mu_{2} / \mu_{1}$ on horizontal dynamic stiffnesses for rigid strip $\left(h / c=2, \nu_{1}=\nu_{2}=1 / 3, \rho_{1}=\rho_{2}\right)$.

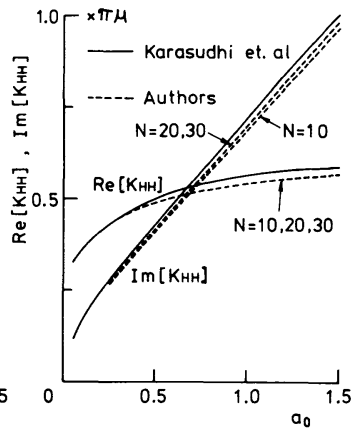

c) Horizontal Vibration
いえよう.

Fig. 4〜6は，表層厚を一 定 $(h / c=2)$ にして, 層剛 性比および接触面の変位拘束 の有無が鉛直，ロッキングお よび水平振動の複素剛性に及 ぼす影響を調べたものであ る.なお，Fig. 5，6では $\mu_{2} / \mu_{1}=2$ に対する結果は図 がふくそうするため省略して ある. 全般的な傾向として， $\mu_{2} / \mu_{1}=10$ の場合の複素剛性 は, 半無限弾性地盤 $\left(\mu_{2} / \mu_{1}\right.$ =1）のそれに比べて無次元加振振動数 $a_{0}\left(=\omega c / V_{S 1}\right)$ の影響を受けている．二層弾性地盤に対するこれらの現 象は，表層地盤の振動特性に起因しているものと考えら れる。いま，Fig. 2 の分散曲線において，下層が剛基盤 $\left(\mu_{2} / \mu_{1}=\infty\right)$ の場合には，群速度が 0 となる $\omega h / V_{S 1}$ $\fallingdotseq 3.057 ， 7.745$ および分散曲線と横軸の交点 $\omega h / V_{S 1}=$ $(2 n-1) \pi / 2,(2 n-1) \pi$ (ただし， $n=1,2, \cdots)$ のい ずれかの振動数のとき表層地盤に共振現象が生じること が知られている ${ }^{5)}$ 。したがって，二層地盤において $\mu_{2} / \mu_{1}$ の值が大きくなるほど，表層地盤の振動増幅によ る影響が強く現われることになる．次に， $a_{0}$ の值が小 さい範囲では，いずれの場合も接触面の変位拘束の有無 による複素剛性の差異はほとんどないが， $a_{0}$ の值が大 きくなるとともにその差異は大きくなる傾向にある．ま た，層剛性比が大きくなるとともに $\left(\mu_{2} / \mu_{1}=2\right.$ に対す るロッキング，水平振動の結果は Fig. 8, 9 参照)，接触 面の変位拘束の有無による差異は大きくなる傾向となっ ている.

Fig. 7〜9は，層剛性比を一定 $\left(\mu_{2} / \mu_{1}=2\right)$ にして，

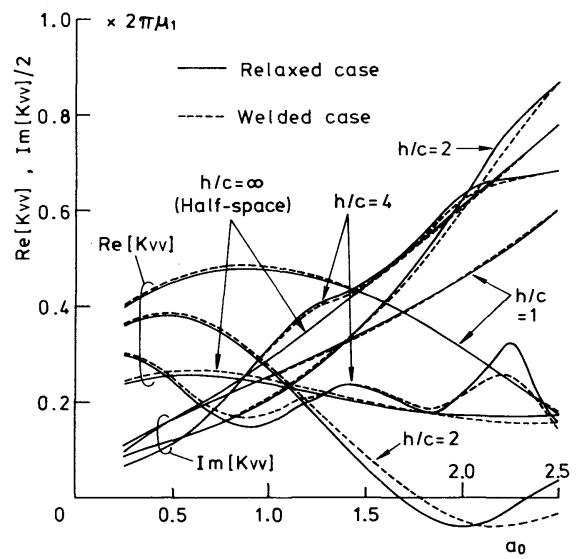

Fig. 7 Effect of $h / c$ on vertical dynamic stiffnessess for rigid strip $\left(\mu_{2} / \mu_{1}=2, \quad \nu_{1}=\nu_{2}=1 / 3, \quad \rho_{1}=\rho_{2}\right)$ 


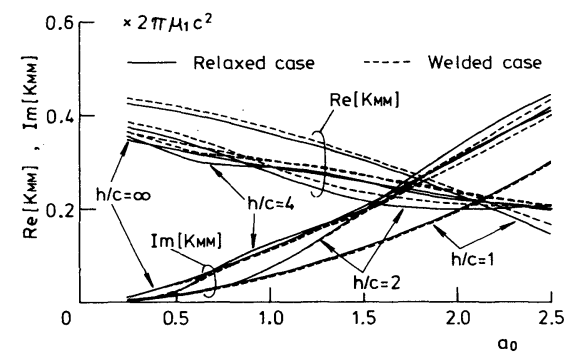

Fig. 8 Effect of $h / c$ on rocking dynamic stiffnesses for rigid strip $\left(\mu_{2} / \mu_{1}=2, \quad \nu_{1}=\nu_{2}=1 / 3, \rho_{1}=\rho_{2}\right)$.

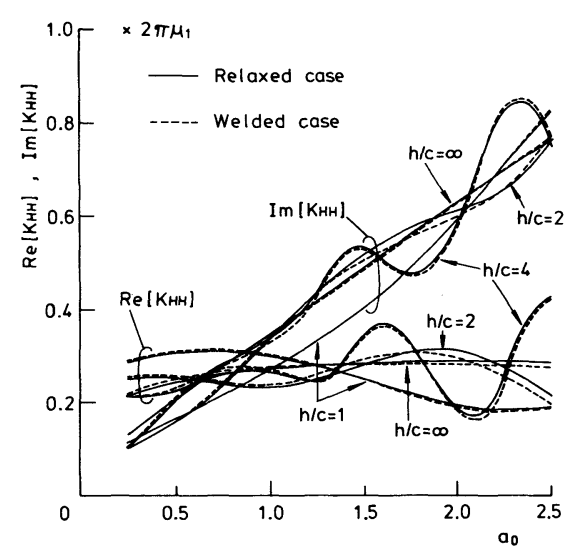

Fig. 9 Effect of $h / c$ on horizontal dynamic stiffnesses for rigid strip $\left(\mu_{2} / \mu_{1}=2, \nu_{1}=\nu_{2}=1 / 3, \rho_{1}=\rho_{2}\right)$.

表層厚 $h / c$ および接触面の変位拘束の有無が複素剛性 に及ぼす影響を調べたものである．これらの図より， $h / c=4$ の場合の複素剛性は, 半無限弾性地盤 $(h / c=$ の) の複素剛性の回りに変動していることがわかる. 特 に，鉛直およびロッキング振動の場合には，h/cの值 が大きくなるとともに二層 弾性地盤の複素剛性が半無 限弾性地盤のそれに近づく 様子が顕著である. 一方, $h / c$ の值が小さい場合で も， $a_{0}$ の值が大きくなる とともに, 表層厚は波長に 比べて相対的に大きくな る. したがって, $h / c=1$ の場合でも， $a_{0}$ の值が大 きくなるとともに複素剛性 は半無限弾性地盤のそれに 近づくことが推測できる.

次に, 接触面の変位拘束の 有無が複素剛性に及ぼす影 響は，鉛直，ロッキングお
よび水平振動のそれぞれの場合で若干異なっている．鉛 直振動の場合には $h / c=2,4$ のときに， $a_{0}$ の值の増加 とともに変位拘束の有無による複素剛性の差異が現われ る傾向となっているが, 水平振動の場合には $h / c=2$ の ときにその差異が認められる. また，ロッキング振動の 場合には，h/cのいずれの值においても変位拘束の有 無による複素剛性の差異が一様に現われる傾向となって いる.

以上の結果より，二層弾性地盤上の剛体帯に対する複 素剛性は無次元加振振動数 $a_{0}$, 層剛性比 $\mu_{2} / \mu_{1}$ および 表層厚 $h / c$ 等の影響を受けることがわかる. また, 接 触面の変位拘束の有無が複素剛性に及ぼす影響も表層地 盤の振動特性に関係している. しかし，本論文で示した 諸元の範囲では, 複素剛性に及ぼす接触面の変位拘束の 影響が涊められるもののその程度は少なく，特に $a_{0}$ の 值が小さいときには変位拘束を無視できることがわか る.

\section{4. 正方形剛基礎に対する複素剛性}

長方形底面をもつ岡基礎の場合, 接触面の分割数を増 すことによって, 式 (3) で表わされる影響関数の計算 量が非常に増加する. しかも, 式 (3) は特異点を含む 二重積分の形となるため, 演算コストの面で影響関数の 近似化が必要となる. 本論文では分割要素に正方形を用 い, 式（3）の積分を正方形要素と等価な面積の円形等 分布加振に対する積分で代用した。 なお，これらに対す る諸検討は文献 21）に与えられている. 一方，接触面 の分割数については, その数を増せば厳密解に近づくわ けであるが，本論文では剛基礎の正方形底面を $10 \times 10$ のメッシュに分割した.この分割メッシュの誤差に対す る検討と既往の研究との比較は文献 14）に示されてい

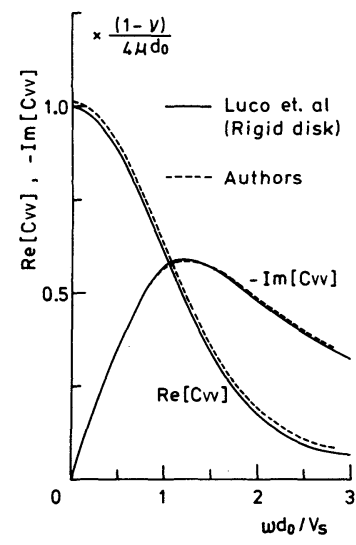

a) Vertical Vibration

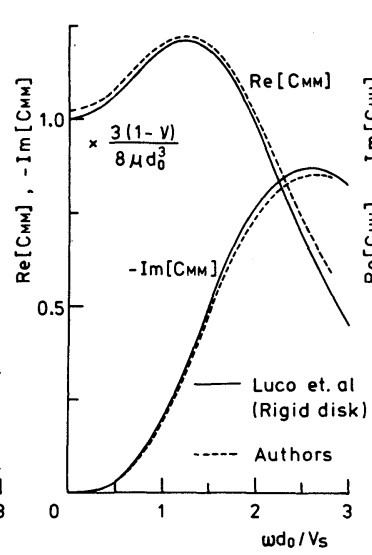

b) Rocking Vibration

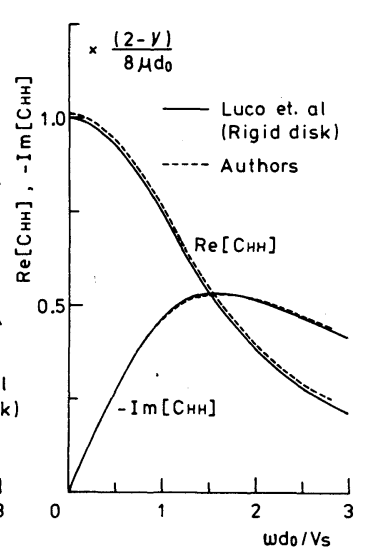

c) Horizontal Vibration
Fig. 10 Comparison of compliances for rigid disk and rigid square foundation (Half-space, Relaxed case, $\nu=1 / 3$ ). 


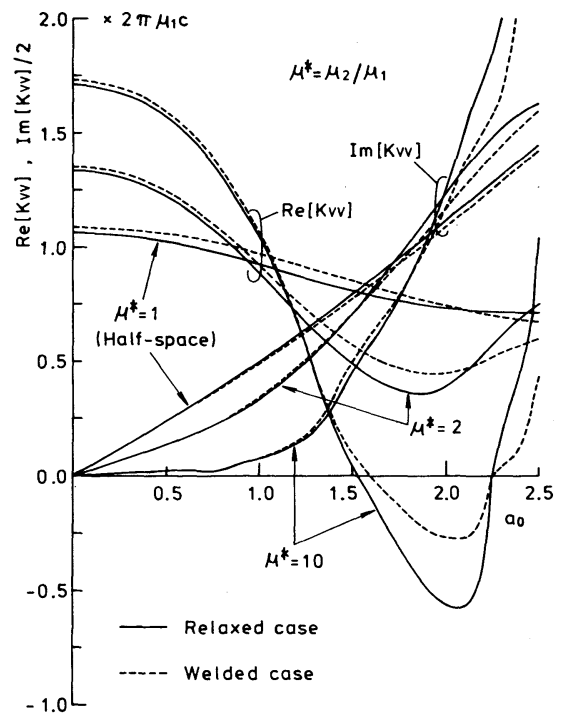

Fig. 11 Effect of $\mu_{2} / \mu_{1}$ on vertical dynamic stiffnesses for rigid square foundation $\left(h / c=2, \quad \nu_{1}=\nu_{2}=1 / 3, \rho_{1}=\rho_{2}\right)$.

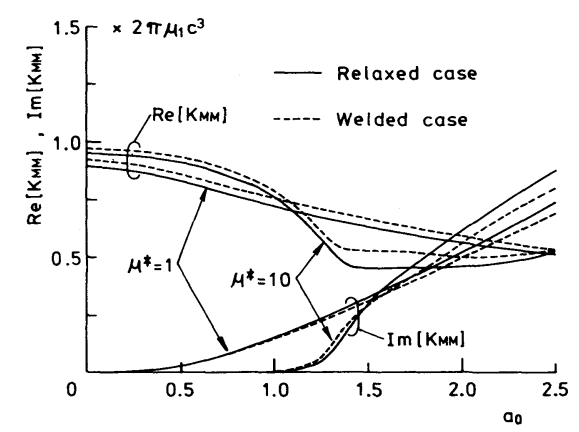

Fig. 12 Effect of $\mu_{2} / \mu_{1}$ on rocking dynamic stiffnesses for rigid square foundation $\left(h / c=2, \nu_{1}=\nu_{2}=1 / 3, \rho_{1}=\rho_{2}\right)$.

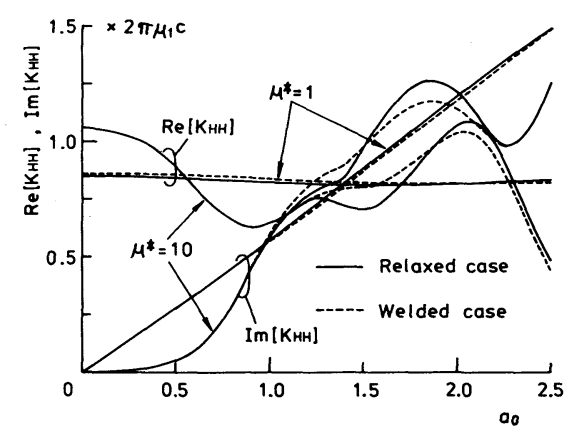

Fig. 13 Effect of $\mu_{2} / \mu_{1}$ on horizontal dynamic stiffnesses for rigid square foundation $\left(h / c=2, \nu_{1}=\nu_{2}=1 / 3, \rho_{1}=\rho_{2}\right)$.

る.

まず, 半無限弾性地盤で接触面の変位拘束を無視した 場合について, Luco ら ${ }^{8)}$ が求めた剛円盤の複素コンプ ライアンス（複素剛性の逆数に相当）と底面積が等価な
正方形剛基礎の複素コンプライアンスの比較を Fig. 10 に示す．正方形剛基礎に対する結果には分割メッシュに よる誤差が含まれるが，両者はよく一致している，一般 に, 円形等分布加振と面積が等価な正方形面に作用する 等分布加振による中央変位はほとんど一致することが知 られている ${ }^{21}$ が, 剛基礎底面の合反力についてもほぼ一 致することがわかる.

Fig. 11〜13 は，表層厚を一定 $(h / c=2)$ にして，層 剛性比および接触面の変位拘束の有無が鉛直, ロッキン グおよび水平振動の複素剛性に及ぼす影響を調べたもの である.これらの影響の全般的な傾向は，Fig. 4 6に 示した剛体帯に対する複素剛性における傾向とよく一致 している. したがって, 表層厚が複素剛性に与える効果 についても剛体帯のそれと同様であろうと推察できる.

また, 接触面の変位拘束を無視した場合について, 二層 弾性地盤の複素剛性の $a_{0}$ の值に対する変動は, $\mathrm{Luco}^{9)}$ が求めた剛円盤に対する結果ともよく一致した傾向を示 している. Fig. 10 の結果を踏まえて, 層状弾性地盤上 の正方形剛基礎底面の複素剛性は, 層状弾性地盤の振動 特性にかかわらず, 底面積が等価な剛円盤の複素剛性で 代用できるといえよう。

\section{5. あとがき}

本論文で示した結果のうち一部は層状弾性地盤に対す る既往の研究成果たとえば5), 91, 19) と同様のものとなっている が，得られた知見を要約すれば次のようになる.

（1）二層弾性地盤の複素剛性は, 地盤の層剛性比 $\mu_{2} / \mu_{1}$ が大きくなるとともに, 表層地盤の振動特性の影 響を受けている ${ }^{5), 9}$.

（2）表層厚 $h / c$ が大きくなるとともに, 二層弾性 地盤の複素剛性は半無限弾性地盤に対する複素剛性に収 束している5),9), 19).

（３）鉛直複素剛性に及ぼす地盤の層剛性比および表 層厚の影響は水平およびロッキングの複素剛性に対する

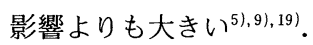

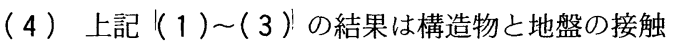
面における変位拘束なしに対するものであるが, 変位拘 束ありの場合にも同じ傾向となっている.

（５）変位拘束の有無による複素剛性の差異は, 地盤 の層剛性比とともに大きくなる傾向にある. 一方, その 差異に及ぼす表層厚の影響は各振動型で異なっている.

（6）本論文で示した諸元の範囲では，複素剛性に及 ぼす変位拘束の影響は認められるもののその程度は少な <, 無次元振動数 $\omega c / V_{s_{3}}$ が小さい範囲では変位拘束を 無視できる.

以上の知見は, 剛体帯の場合および正方形底面をもつ 剛基礎の場合のいずれに対しても得られるものである. 
また，上記（1）～( 3 ）は剛円盤に対する結果 ${ }^{9)}$ と同様 のものであること, 半無限弾性地盤上の正方形剛基礎に 対する複素剛性は底面積が等価な剛円盤のそれとほぼ一 致していることから, 本論文で得られた知見は構造物底 面の形状によって一般性を失うものではない.

\section{参 考 文 献}

1) Richart, F.E., Hall, J.R. and Woods, R. D. (岩崎敏 男・嶋津晃臣共訳)：土と基礎の振動, 鹿島出版会, 1975.

2) Bycroft, G. N. : Forced vibrations of a rigid circular plate on a semi-infinite elastic space and on an elastic stratum, Phil. Trans. Roy. Soc. London, Vol. 248, Series A, pp. 327 368, 1956.

3) 田治見宏: 耐震理論に関する基礎的研究, 東大生産研究 所報告, 第 8 巻, 第 9 号, pp. 170 215, 1959.

4) Thomson, W. T. and Kobori, T. : Dynamic compliance of rectangular foundations on an elastic half-space, J. Appl. Mech., Vol. 30, Trans. ASME, Vol. 85, pp. 579 $\sim 584,1963$.

5）小堀鐸二・南井良一郎・鈴木 有 : 成層構造をもつ基礎 地盤の動特性, 京大防災研究所年報, 第 19 号 B, pp. 167 217, 1976.

6) Karasudhi, P., Keer, L. M. and Lee, S. L. : Vibratory motion of a body on an elastic half plane, J. Appl. Mech., Vol. 35, Trans. ASME, Vol.90, pp. 697 705, 1968.

7) Luco, J.E. and Westmann, R. A. : Dynamic response of a rigid footing bonded to an elastic half space, J. Appl. Mech., Vol. 39, Trans. ASME, Vol.94, pp. 527 $\sim 534,1972$.

8) Luco, J.E. and Westmann, R. A. : Dynamic response of circular footings, Proc. ASCE, Vol.97, EM 5, pp. 1381 1395, 1971.

9) Luco, J. E. : Impedance functions for a rigid foundation on a layered medium, Nuclear Engng Design, Vol.31, pp. 204 217, 1974.

10) Elorduy, J., Nieto, J. A. and Szekely, E. M. : Dynamic response of bases of arbitrary shape subjected to periodic vertical loading, Proc. Int. Symp. on Wave Propagation and Dynamic Properties of Earth Materials, Albuquerque, pp. 105 121, 1967.
11) Wong, H.L. and Luco, J.E. : Dynamic response of rigid foundations of arbitrary shape, Int. J. Earthquake Engng Struct. Dynamics, Vol.4, pp. 579 587, 1976.

12) Savidis, S. A. and Richter, T. : Dynamic interaction of rigid foundations, Proc. 9th Int. Conf. on Soil Mechanics and Found. Engng, Tokyo, Vol.2, pp. 369 374, 1977.

13) Gaul, L. : Dynamische Wechselwirkung eines Fundamentes mit dem viskoelastischen Halbraum, IngenieurArchiv, Vol.46, pp.401 422, 1977.

14) Kitamura, Y. and Sakurai, S. : Dynamic stiffness for rectangular rigid foundations on a semi-infinite elastic medium, Int. J. Numer. Anal. Methods Geomech., Vol. 3, pp. 159 171, 1979.

15）北村泰寿・桜井春輔：剛基礎底面の複素剛性に関する一 解析法, 土木学会論文報告集, 第 290 号, pp. 43 52, 1979.

16) Hamidzadeh-Eraghi, H.R. and Grootenhuis, P. : The dynamics of a rigid foundation on the surface of an elastic half-space, Int. J. Earthquake Engng Struct. Dynamics, Vol. 9, pp. 501 515, 1981.

17) Adeli, H., Hejazi, M.S., Keer, L. M. and NematNasser, S. : Dynamic response of foundation with arbitrary geometries, Proc. ASCE, Vol.107, EM 5, pp. 953 〜967, 1981.

18) Rücker, W. : Dynamic behaviour of rigid foundations of arbitrary shape on a half-space, Int. J. Earthquake Engng Struct. Dynamics, Vol.10, pp. 675 690, 1982.

19) Kawase, H., Yoshida, K., Nakai, S. and Koyanagi, $Y$. : Dynamic response of a structure on a layered medium-A dipping layer and a flat layer-, 第 6 回日 本地震工学シンポジウム, pp. 1641 1648, 1982.

20）川上英二・田崎信一：任意形状の剛基礎底面に対する動 的 Compliance の簡易解析法, 土木学会論文集, 第 350 号, I-2, pp. 253〜262，1984.

21）北村泰寿・桜井春輔：弾性地盤上の構造物の動的解析に おける地盤の柔性マトリックス, 土木学会論文報告集, 第 341 号, pp. 119 127, 1984.

22）北村泰寿 - 桜井春輔 - 陳 徳生：二層弾性体表面の点加 振力による表面変位の解析, 建設工学研究所報告, 第 22 号, pp. 145 166, 1980.

（1984.11.7 • 受付） 